\title{
In Situ Disassembling Behavior of Composite Hydrogels for the Efficient Removal of Crystal Violet Dye from Aqueous Solution
}

\author{
Venkatesan Srinivasan, ${ }^{1}$ Sundaram Thiraviam, ${ }^{1}$ Kullagounder Subramani, ${ }^{2}$ \\ Sibi Srinivasan, ${ }^{1}$ Pragathiswaran Chelliah, ${ }^{3}$ and Stanley Anthuvan Babu ${ }^{1}$ \\ ${ }^{1}$ Department of Chemistry, Adhiyamaan College of Engineering, Hosur, Tamilnadu 635109, India \\ ${ }^{2}$ Department of Chemistry, Islamiah College, Vaniyambadi, Tamilnadu 635751, India \\ ${ }^{3}$ Department of Chemistry, EVR College, Trichy, Tamilnadu 620023, India
}

Correspondence should be addressed to Venkatesan Srinivasan; srini_venkat_msc@yahoo.com

Received 24 December 2013; Accepted 4 February 2014; Published 12 March 2014

Academic Editors: T. R. Chantara, S. Fakirov, R. Scaffaro, and B. G. Soares

Copyright (C) 2014 Venkatesan Srinivasan et al. This is an open access article distributed under the Creative Commons Attribution License, which permits unrestricted use, distribution, and reproduction in any medium, provided the original work is properly cited.

\begin{abstract}
A novel method for the disassembly of synthetic hydrogels in situ and thereby enhanced adsorption of crystal violet dye is reported. Silicon present in the husk ashes of Panicum miliare is used as the trigger for disassembly of poly(2-acrylamido-1-propane sulfonic acid-co-itaconic acid) hydrogels. Disassembling ability of the ash was determined by changing the temperature of the husk ash. Surface area and particle sizes of both the disassembled and assembled forms of the hydrogels were determined by E. Suito's method. Removal of crystal violet dye from aqueous solution and the respective adsorption capacities of disassembled and assembled forms of hydrogels were compared by varying parameters such as $\mathrm{pH}$, temperature, and agitation speed. Concentration of the dye in aqueous solution was determined by using UV-Visible spectrophotometer. FTIR analysis was carried out for the characterization of the hydrogels, ash blended hydrogels, and the free ashes. SEM imaging was carried out to differentiate the surfaces of the assembled and disassembled hydrogels.
\end{abstract}

\section{Introduction}

Many researches are being done on hydrogels to increase and improve their applications in various fields. Crosslinked hydrophilic polymers made hydrogels have capacity for expanding their volumes by their high capacity for water absorption $[1,2]$ that makes them suitable for purification of wastewater, drug delivery [3], and so forth. The use of hydrogels is known since the late 1950s in the form of the bioengineered contact-lenses [4]. Recently hydrogels such as poloxamers are useful in regenerative medicine. The adsorption ability of aromatic organic molecules of the polymer hydrogels [5] has provided a very good option for polymer adsorbents. Like few other hydrogels poly (2-acrylamido-1-propane sulfonic acid-co-itaconic acid) [poly(AMPS-co-IA)] hydrogels are reported to be good adsorbents for the removal of methylene blue dye [6] and few metal ions $[7,8]$ from aqueous solution.
Crystal violet has been largely used in numerous commercial textile processes as a dye and also in human and veterinary medicines as a biological stain $[9,10]$. When discharged into the aquatic system, it can cause severe environmental degradation. The dye has a blue-violet colour with an extinction coefficient of $87,000 \mathrm{M}^{-1} \mathrm{~cm}^{-1}$ and an absorbance maximum at $590 \mathrm{~nm}$ when dissolved in water [11]. Crystal violet has been classified as a recalcitrant. That makes it difficult for the metabolism of living microbes and hence the dye has extended lifetime in various environments [12]. Crystal violet is highly toxic, carcinogenic, and harmful to the skin when in contact. It is also a mutagen and a mitotic poison [13].

Panicum miliare (Pm) (refer to Figures 1(a), 1(b), and 1(c)) is comparable in taste and utility of rice. Pm is one among the food material containing abundant nutrition [14]. Small millets, which belong to the cereals family, provide an easy opportunity for the improving of the health of people. It 


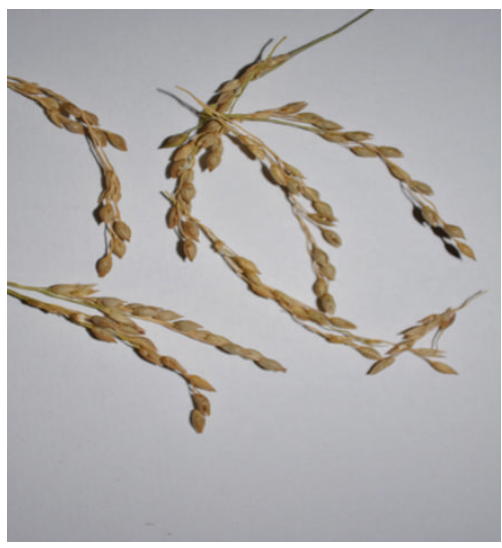

(a)

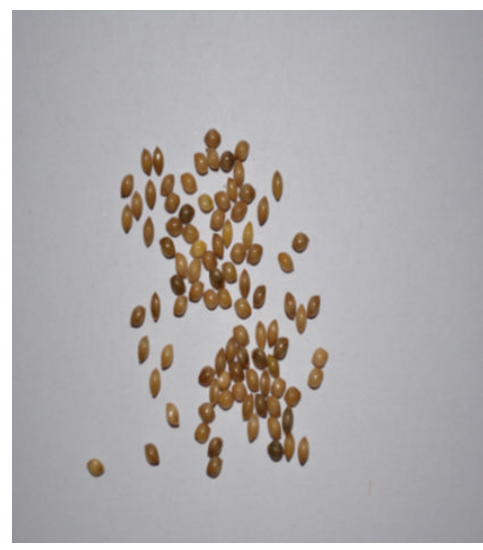

(b)

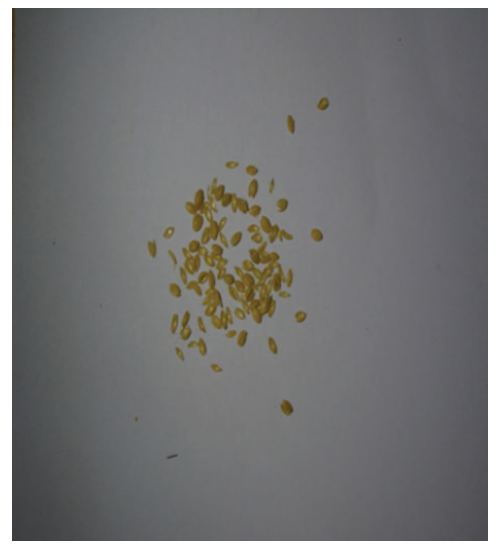

(c)

Figure 1: Pm (a) as obtained from the source plant, (b) Pm before dehusking, and (c) husks of Pm.

reduces the cost of health care because of its medicinal value and at the same time it supports the economic development in tribal and rural communities. reduce health care costs, and support economic development in rural and tribal communities. The fondly called Little Millet is usually cultivated in agricultural land, situated at least 2000 feet above the sea level. Farmers in Southern parts of India have the habit of cultivating this grain. The dehusked part of the millet is a food source for little birds such as sparrows and love birds, whereas the husks are just useful for nothing. In this study, we have shown that the husk ash of the same millet can be a potential source of silicon. This agricultural waste is weighing $0.0005-0.0006 \mathrm{~g}$ per husk. Much is not known by the scientific community about this biowaste owing to the negligible abundance and rare utilization.

In this study poly(AMPS-co-IA) hydrogels are used as the adsorbent for the removal of crystal violet dye from aqueous solution. When put into an aqueous solution, this polymer hydrogels were disassembled into smaller units by the inclusion of husk ash into their network. These husk ashes were obtained by dehusking Pm and heating them strongly. The ability of the husk ashes to disassemble the hydrogels was identified by changing the temperature of heating the husk ash and including those ashes into the network of hydrogels. The husk ashes heated to strong temperatures were found as the only useful material for disassembling purposes whereas the ashes heated to lower temperatures were found ineffective for this job. The reason behind the unusual property of disassembling the hydrogels is identified by FTIR study of the free hydrogels, blended hydrogels, and free husk ashes. A comparison of efficiency in adsorption of dye is made between the assembled and disassembled form of the hydrogels. Variation in the adsorption of the dye with respect to agitation speed, $\mathrm{pH}$, and temperature of the system is reported.

\section{Experimental}

2.1. Materials. 2-Acrylamido-2-methyl-1-propane sulfonic acid (AMPS) (99\%, Aldrich) m.p. 194-196 ${ }^{\circ} \mathrm{C}$ and itaconic acid (IA) (99\%, Aldrich), m.p. $166-167^{\circ} \mathrm{C}$, were the monomers. Potassium persulfate $(99.99 \%$, trace metals basis, Aldrich), m.p $99^{\circ} \mathrm{C}$ to $100^{\circ} \mathrm{C}$, the initiator, and N,Nmethylenebisacrylamide (MBAAm) (99\%, Aldrich) m.p. $301-303^{\circ} \mathrm{C}$, the cross-linker, were all used as obtained. Crystal violet dye (99\%, Aldrich) was used as the adsorbent. Pm was purchased from the local shop and was used after dehusking and bleaching several times with hydrochloric acid and finally washing with double distilled water.

2.2. Synthesis of the Hydrogels Samples. Poly(AMPS-co-IA) hydrogels were synthesized by free radical copolymerization [6]. $1.6560 \mathrm{~g}$ of AMPS and $0.2615 \mathrm{~g}$ of IA were cross-linked using $0.1540 \mathrm{~g}$ of MBAAm as the cross-linker and $0.0400 \mathrm{~g}$ of potassium persulfate as free radical initiator and all the ingredients were made into a $10 \mathrm{~mL}$ solution, using double distilled water in a $10 \mathrm{~mL}$ measuring jar. All of them were then transferred into a $250 \mathrm{~mL}$ beaker placed upon a heating plate. The contents were well mixed and accompanied with a heating rate of $2^{\circ} \mathrm{C} / \mathrm{min}$ for about 15 minutes, using a sterile glass rod for continuous stirring. An increase in viscosity after 10 minutes was observed. A transparent gel was formed after 15 minutes and was placed in hot air-oven, to complete the cross-linking process. After 24 hours of heating in the airoven at $50-55^{\circ} \mathrm{C}$, the hydrogels were removed and then purified using soxhlet apparatus, using water as the solvent, for 24 hours for removing the uncross-linked and water soluble substances, if any. The efficiency of cross-linking was found using the following formula:

$$
\text { Efficiency of crosslinking }=\frac{\left(W_{a}-W_{b}\right)}{W_{a}} \times 100,
$$

where $W_{a}$ and $W_{b}$ are the weights in grams of dried hydrogels before and after introducing to Soxhlet apparatus, respectively.

2.3. Preparation of Ash. The Pm purchased from the local shop was dehusked with the help of Agapornis (love birds). These birds have the habit of eating Pm by dehusking the 


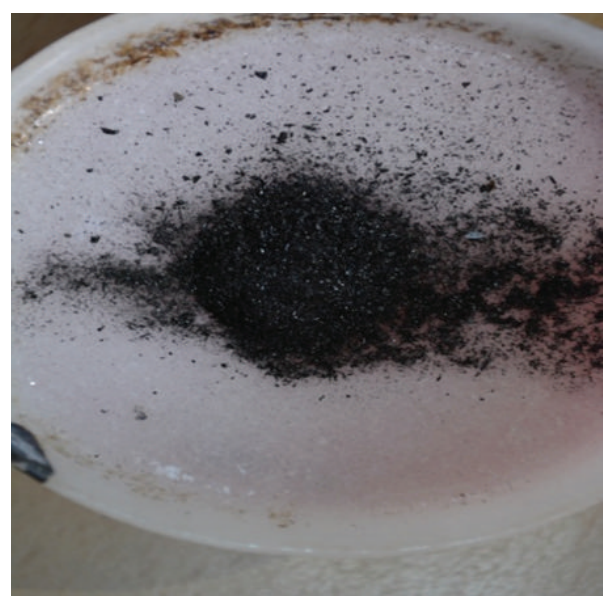

(a)

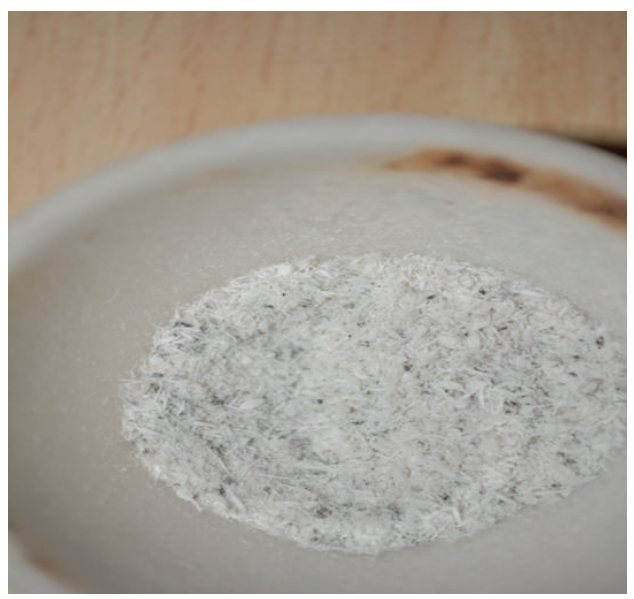

(b)

Figure 2: (a) Ash I and (b) ash II.

TABLE 1: Different types of ashes produced from Panicum miliare husks.

\begin{tabular}{lccc}
\hline $\begin{array}{l}\text { Type of } \\
\text { the ash }\end{array}$ & $\begin{array}{c}\text { Temperature } \\
\text { of heating }\end{array}$ & $\begin{array}{l}\text { Time of } \\
\text { heating }\end{array}$ & $\begin{array}{c}\text { Colour } \\
\text { observed }\end{array}$ \\
\hline Ash I & $250^{\circ} \mathrm{C}$ & 6 hours & Black \\
Ash II & $1000^{\circ} \mathrm{C}$ & 6 hours & White \\
\hline
\end{tabular}

millet with their mouth. The husks are never eaten by them even their owners use them for no purpose. Excreta, dust and other particles in the husk were cleaned manually first and then washed with double distilled water to remove all water soluble impurities. These were then washed with $0.1 \mathrm{~N}$ $\mathrm{HCl}$ five times repeatedly for better cleaning. The husks were separated into three parts and heated using a muffle furnace to different temperatures (see Figure 2 and Table 1).

2.4. Synthesis of Ash Blended Hydrogels. The ingredients and procedure for the synthesis of poly(AMPS-co-IA) was followed as such, except for the addition of ashes of husks as in Table 2.

AMPS, IA, $\mathrm{K}_{2} \mathrm{SO}_{4}$, and MBA were mixed with definite quantity of black ash dispersed [24] in double distilled water; hence, the whole dispersion was calibrated to $10 \mathrm{~mL}$, using a measuring jar. This dispersion was transferred into a clean $250 \mathrm{~mL}$ Borosil beaker and heated on a heating plate at $2^{\circ} \mathrm{C} / \mathrm{min}$ accompanied with continuous stirring using a glass rod for about 15 minutes; a viscous solution was observed and the stirring continued, even after removing from the heating plate, to ensure that there were uniform mixing of husk ashes into the network of the polymer.

Hydrogels blended with ash II were also prepared similarly. All the ash blended hydrogels were kept in a hot air oven for 24 hours at $50-55^{\circ} \mathrm{C}$ to ensure cross-linking. They were used for further studies as such removed from the oven.

2.5. Surface and Particle Size Studies. Surface area and particle size of the hydrogels was determined by comparing the adsorption efficiency of the adsorbent towards crystal violet dye, using Suito's method [25].

$$
\begin{gathered}
S_{w}=10^{-20} n \cdot a / g \\
n=V_{m} \cdot A / M,
\end{gathered}
$$

where $S_{w}=$ specific surface area of the adsorbent in $\mathrm{m}^{2} / \mathrm{g}, V_{m}$ = volume occupied by the adsorbate, $A=$ Avogadro number; $M=$ molecular weight of the adsorbate, $g=$ amount of the adsorbent used in grams; $n=$ number of molecules adsorbed, $a=21 \AA^{2}$, and $10^{-20}$ is the conversion factor for $\AA^{2}$ units and $\mathrm{m}^{2}$.

Particle size was determined from the following formula:

$$
d_{m}=\frac{6}{\varrho} S_{w}
$$

where $\varrho$ is density of the sample adsorbent; $d_{m}$ is diameter of the particle in $\mu$.

2.6. Swelling Index. Swelling index of hydrogels studied by introducing the polymer into double distilled water. The following formula was used for determining the swelling index of the hydrogels [26].

$$
\text { Swelling index }=\frac{\left(W_{i}-W_{i i}\right)}{W_{i}} \times 100,
$$

where $W_{i}$ is the weight of the wet swollen hydrogel and $W_{i i}$ is the weight of the dried hydrogels.

2.7. Measurements. FTIR spectra of the hydrogels were recorded with Perkin Elmer Spectrum 1 FT-IR instrument with a typical resolution of $1.0 \mathrm{~cm}^{-1}$ using $\mathrm{KBr}$ (Potassium Bromide) disc in the range of $4000-400 \mathrm{~cm}^{-1}$. All the free hydrogels, composite hydrogels with black ash, and the composite hydrogels with white ash were dried at $50-55^{\circ} \mathrm{C}$ for 12 hours and ground well using a mortar and then subjected 
TABle 2: Composition of black ash blended hydrogels.

\begin{tabular}{|c|c|c|c|c|}
\hline Name of the composite hydrogels & Ash content in grams & AMPS & MBA & $\mathrm{K}_{2} \mathrm{SO}_{4}$ \\
\hline Black ash 0.5 & 0.0106 & $1.6560 \mathrm{~g}$ & $0.2615 \mathrm{~g}$ & $0.1540 \mathrm{~g}$ \\
\hline Black ash 1.0 & 0.0212 & $1.6560 \mathrm{~g}$ & $0.2615 \mathrm{~g}$ & $0.1540 \mathrm{~g}$ \\
\hline Black ash 1.5 & 0.0318 & $1.6560 \mathrm{~g}$ & $0.2615 \mathrm{~g}$ & $0.1540 \mathrm{~g}$ \\
\hline Black ash 2.0 & 0.0423 & $1.6560 \mathrm{~g}$ & $0.2615 \mathrm{~g}$ & $0.1540 \mathrm{~g}$ \\
\hline Black ash 2.5 & 0.0530 & $1.6560 \mathrm{~g}$ & $0.2615 \mathrm{~g}$ & $0.1540 \mathrm{~g}$ \\
\hline Black ash 3.0 & 0.0636 & $1.6560 \mathrm{~g}$ & $0.2615 \mathrm{~g}$ & $0.1540 \mathrm{~g}$ \\
\hline Black ash 3.5 & 0.0742 & $1.6560 \mathrm{~g}$ & $0.2615 \mathrm{~g}$ & $0.1540 \mathrm{~g}$ \\
\hline
\end{tabular}

TABLE 3: Behavior of blended and nonblended hydrogels in water.

\begin{tabular}{lccc}
\hline $\begin{array}{l}\text { Type of ash blended } \\
\text { with hydrogels }\end{array}$ & Percentage of Ash & Swelling index & Disassembly \\
\hline No ash & - & 600 g of water & Not observed \\
Black ash & 0.5 & 723 g of water & Not observed \\
White ash & 0.5 & 900 g of water & Observed \\
\hline
\end{tabular}

to FTIR study. UV (ultra violet) spectrum was recorded for the determination of concentration of the dyes in the aqueous solution in the range 150-450 nm using UV-Visible spectrophotometer. The $\mathrm{pH}$ study was done with ELICO LI $120 \mathrm{pH}$ meter. Surface morphological imaging of the hydrogels was examined by Scanning Electron Microscopy, SEM (JSM 561OLV, JEOL).

2.8. Adsorption Studies. The batch experiments were carried out in $100 \mathrm{~mL}$ Erlenmeyer flasks by agitating $0.1 \mathrm{~g}$ of the dried hydrogels with $25 \mathrm{~mL}$ of the aqueous crystal violet solution for a predetermined period at $28^{\circ} \mathrm{C}$ on a water bathcum-mechanical shaker. The hydrogels were separated by a filter paper from the rest solution, after the adsorption was completed. The effect of $\mathrm{pH}$, agitation speed, and temperature were studied. $0.1 \mathrm{~N} \mathrm{HCl}$ and $0.1 \mathrm{~N} \mathrm{NaOH}$ solutions were used for $\mathrm{pH}$ adjustments. The concentration of crystal violet dye was determined by UV-Visible spectrophotometer. The adsorption of the dye was calculated from the differences in concentrations of the fresh and adsorbed solution.

The amount of crystal violet dye adsorbed by adsorbents was calculated using the difference in their masses as per the following formula:

$$
\% R=\frac{\left(C_{i}-C_{i i}\right)}{C_{i}} \times 100,
$$

where $\% R$ is the removal percentage and $C_{i}$ and $C_{i i}$ are the concentrations of dye before and after the adsorption process.

\section{Result and Discussion}

3.1. Study of Hydrogels in Aqueous Solution. The principle focus of this study was to identify the impact of ashes in the network of the polymer hydrogels. $1.0 \mathrm{~g}$ of dried hydrogels, which were already blended with the two types of ashes, were put into series of beakers containing $50 \mathrm{~mL}$ of double distilled water in each (See Figure 3).
Another set of experiments was also conducted simultaneously with hydrogels without ash blend to find the variations. The changes were noted in Table 3.

The criterion for the word "disassembly observed" was that the original size of the hydrogels was disintegrated into smaller pieces immediately when put into the aqueous solution. It was inferred from Table 3 that the disassembly is observed only with white ash type. This was not seen with the hydrogels without any ash content, when put into the aqueous solution. The disassembly was also not observed for the black ash blended hydrogels, as evident from Table 3. In the latter case, that is, with white husk ash composite hydrogels, disassembly of hydrogels when introduced into aqueous solution was observed. This implies that the affinity towards water for certain species available with white ash blended hydrogels should have been the driving force for disassembling the hydrogels.

The observed improvement in the swelling index of the resulting hydrogels implies that the water intake capacity increases with black ash composite and it further increases when disassembled by white ash (See Figure 4).

3.2. Characterization of the Disassembled Hydrogels. To find the reason behind the ability of blended hydrogels with white ash to get disassembled in situ in aqueous solution, FTIR characterization was done. Characterization was carried out for the composite hydrogels sample prior to the introduction into aqueous solution. The bonds that are responsible for the disassembly to occur are determined using the resulting spectrum. Figures 5(c) and 6(c) are showing the FTIR spectrum of free black ash and free white ash, respectively. The strong peak at $1098 \mathrm{~cm}^{-1}$ with black ash shows the presence of $\mathrm{Si}-\mathrm{C}-\mathrm{Si}$ bond. The sharp peak at $1100 \mathrm{~cm}^{-1}$ with white ash shows the $\mathrm{Si}-\mathrm{O}-\mathrm{Si}$ bond. The sharpness helps to distinguish it from $\mathrm{Si}-\mathrm{C}-\mathrm{Si}$ band $[27,28]$. The sharp band at $3420 \mathrm{~cm}^{-1}$ shows the stretching $\mathrm{Si}-\mathrm{OH}$ bond that is hydrogen bonded and not free $\mathrm{Si}-\mathrm{OH}$ bond. 


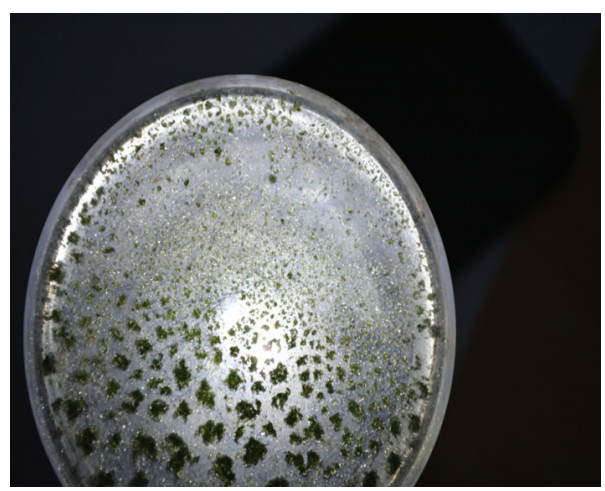

(a)

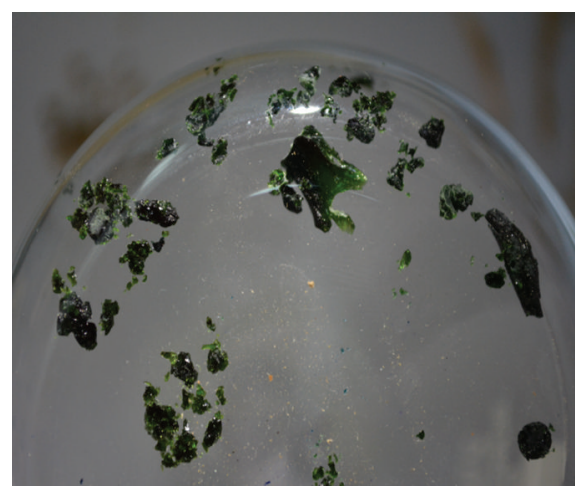

(b)

Figure 3: (a) Dried disassembled hydrogels and (b) dried assembled hydrogels. (Photograph taken after the adsorption of crystal violet dye from aqueous solution by the respective form of hydrogels. Since the hydrogels are colourless, dye adsorbed hydrogels were preferred for distinction.)

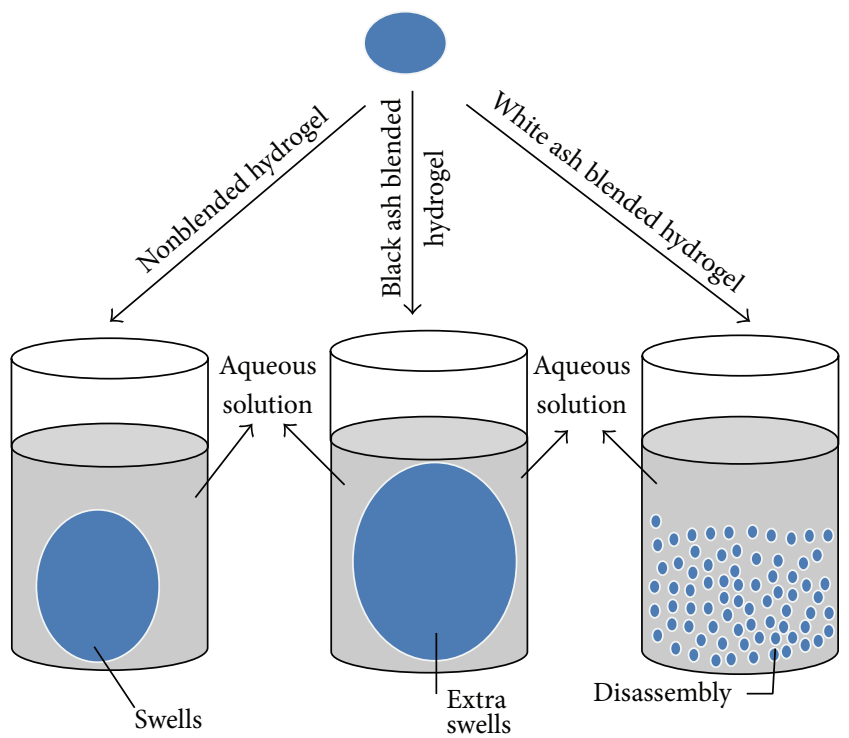

FIGURE 4: Schematic diagram of in situ disassembly of hydrogels in aqueous solutions.

Husks of Pm having organic contents with them were charred after subjecting into $400^{\circ} \mathrm{C}$ temperature for 12 hours. It became black coloured and was named black ash. The temperature of heating the black ash was lesser than its white ash counterpart; therefore, much of the content including carbon in the husk ashes was not removed completely. The presence of carbon content is ensured by the characteristic peak of $\mathrm{Si}-\mathrm{C}-\mathrm{Si}$ as appearing in Figure 5(c). By the inclusion of such black ash into the network of hydrogels, there was no problem for its chemical structure. This was confirmed by comparison of FTIR of free hydrogels and black ash composite hydrogels shown in Figures 5(a) and 5(b). (See Table 4).

Broadband in the range of $3550 \mathrm{~cm}^{-1}$ to $3350 \mathrm{~cm}^{-1}$ shows the existence of $\mathrm{H}$-bonding in the free hydrogels [6]. In the case of composite hydrogels with black ash, $\mathrm{C}=\mathrm{O}$ bond of IA moves from $1723 \mathrm{~cm}^{-1}$ to $1728 \mathrm{~cm}^{-1}$ showing an increase in bond strength because of the ash composite. Sulfonate groups, being strongly ionisable, are responsible for the adsorption process.

A broadband at $1100 \mathrm{~cm}^{-1}$ in the FTIR spectra of white ash shows the presence of $\mathrm{C}-\mathrm{O}-\mathrm{Si}$ bonds and the interaction of the same with the hydrogels showed a peak at $1109 \mathrm{~cm}^{-1}$ instead of a $\mathrm{C}=\mathrm{O}$ stretching frequency at $1723 \mathrm{~cm}^{-1}$. This shows that $\mathrm{C}=\mathrm{O}$ bond of IA has been converted into $\mathrm{C}-\mathrm{O}-$ $\mathrm{Si}$. This conversion is the key factor for the disassembly of the hydrogels. Because the silicon moiety is more hydrophilic than the carbon moiety. The kind of sound that is audible when well-dried bricks are introduced into a bucket of water can be because of the greater affinity of the silicon moiety in the network of bricks. A similar kind of sound was also heard when the white ash composite hydrogels were introduced into the water. By the inclusion of white ash and thereby "Si" moiety directly into the network of the hydrogels, the disassembly is favored when introduced into the vessel containing aqueous solution. Such a disassembly is not possible when the hydrogels was used alone or used as the composite of black ash. Black ash being the substance with greater carbon content, the composite becomes good with only its swelling index [24]. The surface water affinity determines the physical and chemical properties of water adsorbed material. Controlling and modifying such surface water affinity can lead to new nanoscale applications in future. Formation of Si-based surface on hydrogel that absorb the water molecule leads to hydrogels getting disassembled into smaller pieces [29].

3.3. Surface Anatomy of Hydrogels. The surface of the hydrogels is an important criterion in the adsorption process. We have noted an increase in surface area of the polymer after having disassembled. SEM images revealed that the surface of the small disassembled hydrogels was found to be rough and those of the assembled hydrogels were not so. The literature shows that, apart from the influence of other factors such as cross-linker in determining the surface area, the manner of the disassembly process can also lead to the surface change 


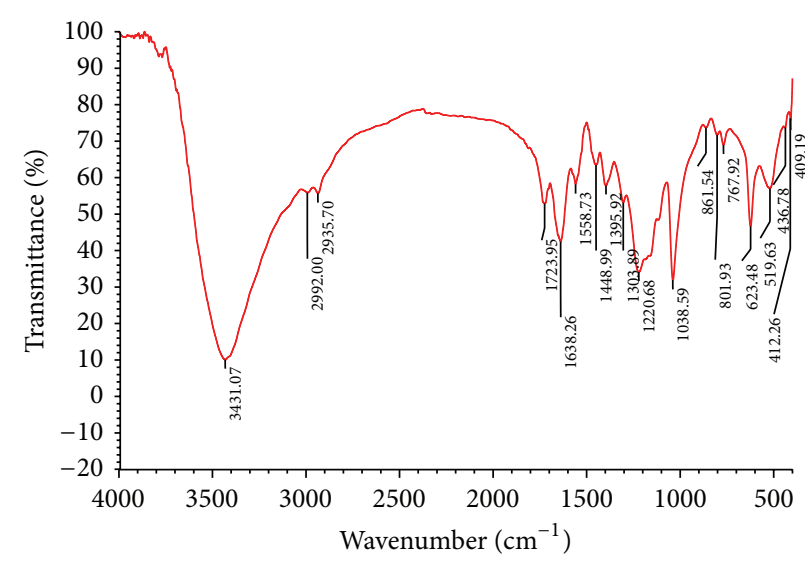

(a)

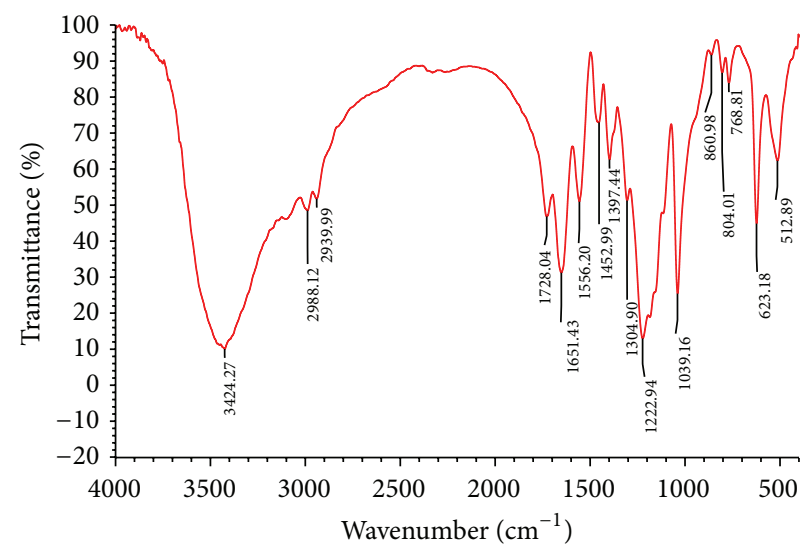

(b)

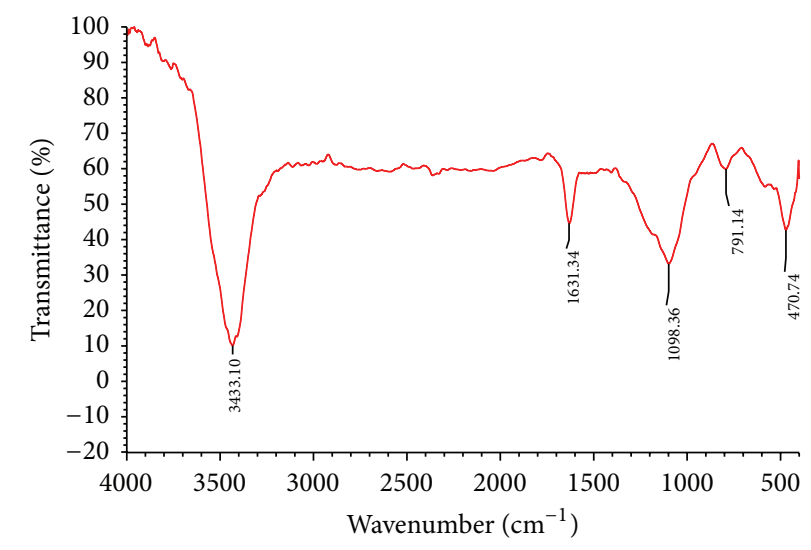

(c)

FIGURE 5: Interactions of hydrogels with black ash. (a) FTIR spectrum of free hydrogels, (b) hydrogels composite with black ash, and (c) free black ash (from top to bottom) ( $x$-axis $=$ wavenumber and $y$-axis $=\%$ transmittance).

TABLE 4: Changes observed at FTIR frequencies observed with free hydrogels and ash composites.

\begin{tabular}{|c|c|c|c|}
\hline Type of frequency & Free hydrogels $\left(\mathrm{cm}^{-1}\right)$ & $\begin{array}{l}\text { Black ash composite } \\
\text { hydrogels }\left(\mathrm{cm}^{-1}\right)\end{array}$ & $\begin{array}{l}\text { White ash composite } \\
\text { hydrogels }\left(\mathrm{cm}^{-1}\right)\end{array}$ \\
\hline $\mathrm{N}-\mathrm{H}, \mathrm{O}-\mathrm{H}$ bonds [15-17] & 3431 & $\begin{array}{l}3424 \text { (intensity } \\
\text { increases) }\end{array}$ & 3429 \\
\hline $\begin{array}{l}\mathrm{C}=\mathrm{O} \text { stretching vibration in amide } \\
\text { groups (amide-I) [15-18] }\end{array}$ & 1638 & 1651 & 1643 \\
\hline Bending of N-H bond (amide-II) & 1558 & 1555 & 1556 \\
\hline C-N bond (amide-III) & 1448 & 1452 & 1454 \\
\hline $\begin{array}{l}\text { Symmetric and asymmetric } \\
\text { stretching of }-\mathrm{SO}_{2}\end{array}$ & 1220 and 1038 & 1222 and 1039 & 1223 and 1037 \\
\hline $\begin{array}{l}\mathrm{C}=\mathrm{O} \text { bond of Carboxyl group } \\
{[19-23]}\end{array}$ & 1723 & 1728 & Do not appear \\
\hline $\mathrm{C}-\mathrm{O}-\mathrm{Si}$ stretching & Do not appear & Do not appear & 1109 \\
\hline
\end{tabular}

$[30,31]$. Therefore, because of the random disintegration of the hydrogels by the speed of water affinity of the "Si moiety" presence in the network of hydrogels, the surface of the hydrogels might have become rough. The process should have occurred similar to a little bombardment. if we imagine the disassembling action of the hydrogels in aqueous solution to be smooth, the surface of the disassembled hydrogels could have been a polished one and not rough. Figures 7(a) and 7(b) clearly shows the above fact. Surface area of the bulk hydrogels was found to be $1.1 \mathrm{~m}^{2} / \mathrm{g}$ and the disassembly hydrogels was found to be $28.3 \mathrm{~m}^{2} / \mathrm{g}$.

3.4. Particle Size versus Percentage of White Ash. To find the impact of white ash content in hydrogels, disassembly was 


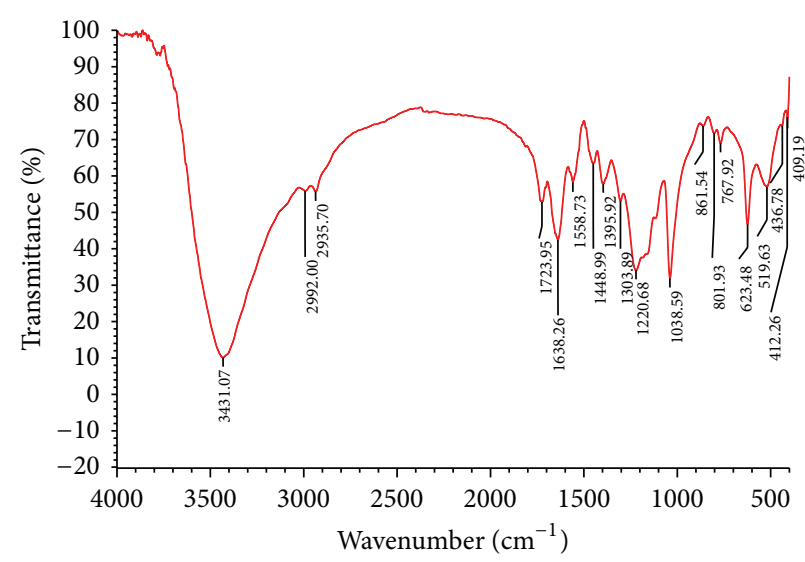

(a)

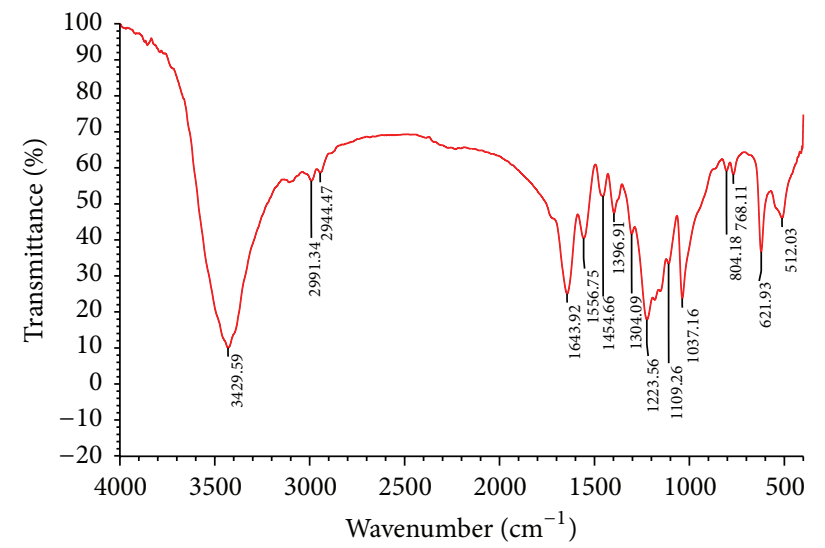

(b)

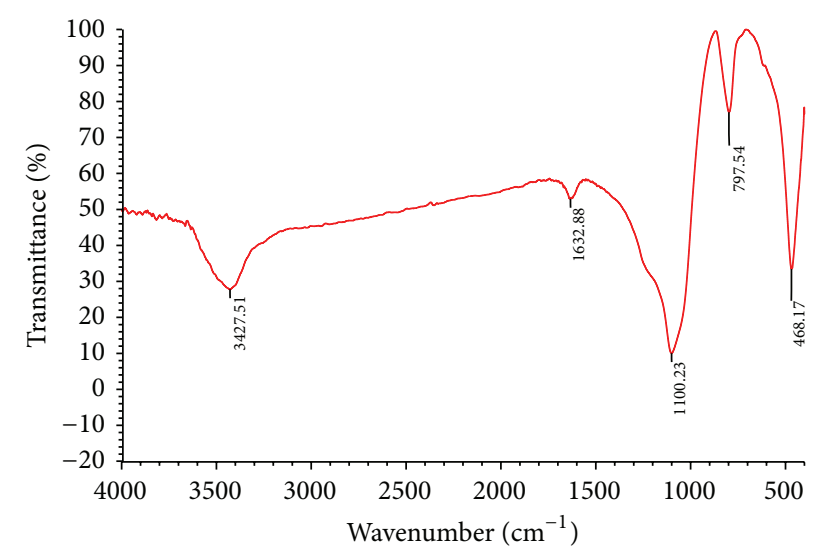

(c)

FIGURE 6: (Figures from (a) to (c) interactions of hydrogels with white ash) (a) free hydrogels*, (b) hydrogels composite with white ash, and (c) free white ash $(x \text {-axis }=\text { wavenumber and } y \text {-axis }=\% \text { transmittance })^{*}$ (Figure $5($ a) repeated for reference purpose).

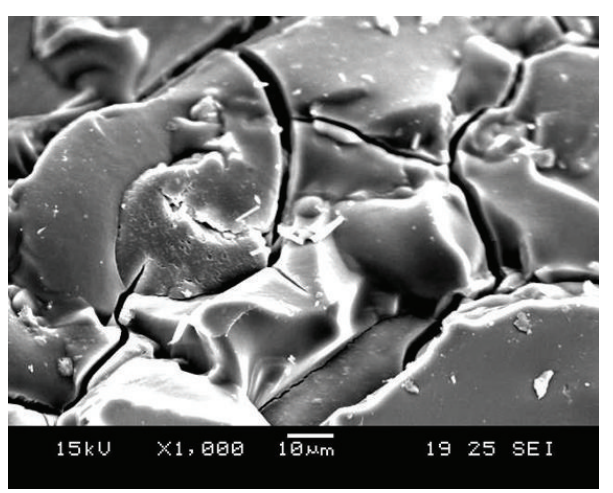

(a)

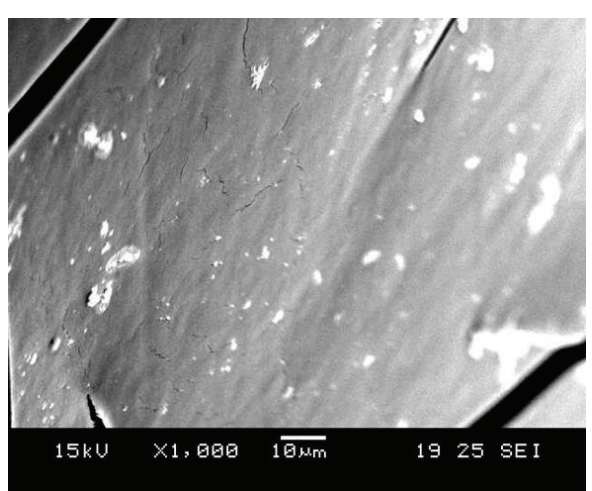

(b)

FIGURE 7: (a) SEM image of disassembled hydrogels and (b) SEM image of assembled hydrogels.

studied by increasing the quantity of white ash from $1 \%$ to $10 \%$. An increase in quantity of disassembly hydrogels and a decrease in size of the resulting particle were observed. The increase in surface area was observed consequently.

Figure 8 shows the variations in particle size with temperature $27^{\circ} \mathrm{C}$ and $\mathrm{pH}=7.1$. Disassembly of other hydrogels like dendrimer hydrogels was also reported [32], but it takes place in a basic medium and without any more actions. Disassembly observed for this hydrogels is a different case, since it happens to the force provided by the hygroscopic nature of silica that is made available within the network of the composite hydrogels.

Particle size, volume occupied by the adsorbate, and surface area of the hydrogels were determined by Suito's 


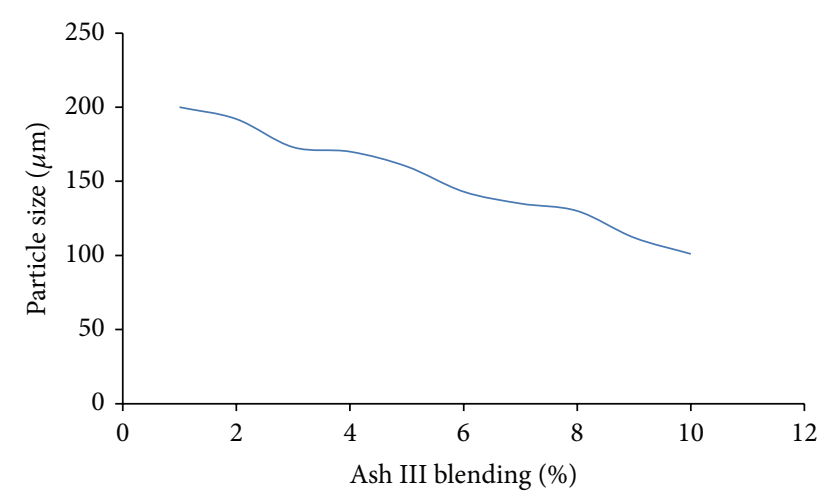

Figure 8: Variation of particle size with respect to white ash blending percentage.

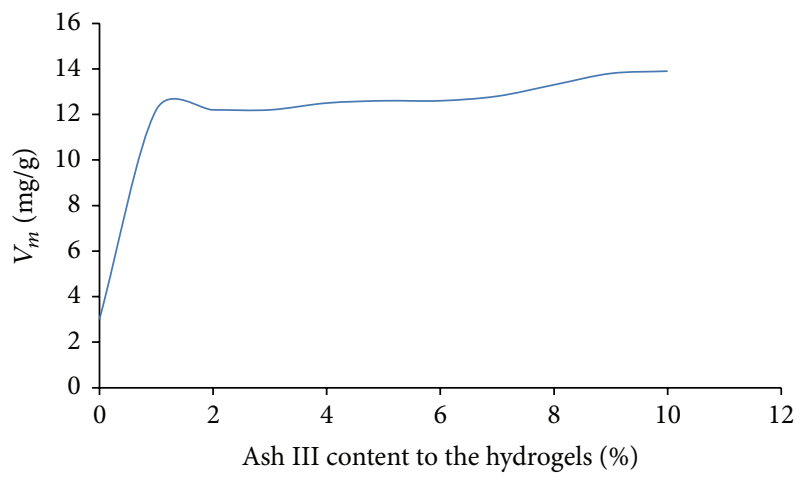

FIGURE 9: Variation of $V_{m}$ with respect to white ash blending.

method. From Figure 8 it is evident that the size of the particle decreases with an increase in the percentage of white ash contents in the network of the hydrogels. Regular variation in the particle sizes implies that the percentage of white ash content increases the degree of disassembly of the hydrogels when introduced into aqueous solution. The least size of the disassembled composite hydrogels particle was observed by 9.8\% of white ash as $103 \mu \mathrm{m}$.

It was also noted from Figure 9 that the volume occupied by the crystal violet dye, which is the adsorbate here, increases with the percentage of white ash content up to $1 \%$, but is found to maintain almost constant afterwards. The maximum volume of the crystal violet dye owing to adsorption was found with $10 \%$ white ash composite hydrogels as $14.1 \mathrm{mg} / \mathrm{g}$.

\subsection{Effect of $p H$ and Temperature on Disassembly of Hydro-} gels. Hydrogels were introduced into a series of solutions maintaining different $\mathrm{pHs}$ and temperatures. It was found that the $\mathrm{pH}$ had no effect in determining the disassembly of the hydrogels. Moreover, the disassembly of hydrogels was also not affected by changing the $\mathrm{pH}$ of the solution. But an increase in temperature to above $60^{\circ} \mathrm{C}$ resulted in a sudden decrease of surface area owing to the start of the reassembly of the polymer into major units. This is because hydrogels start melting after $60^{\circ} \mathrm{C}$ and these molten hydrogels become indistinguishable from each other and mix as a

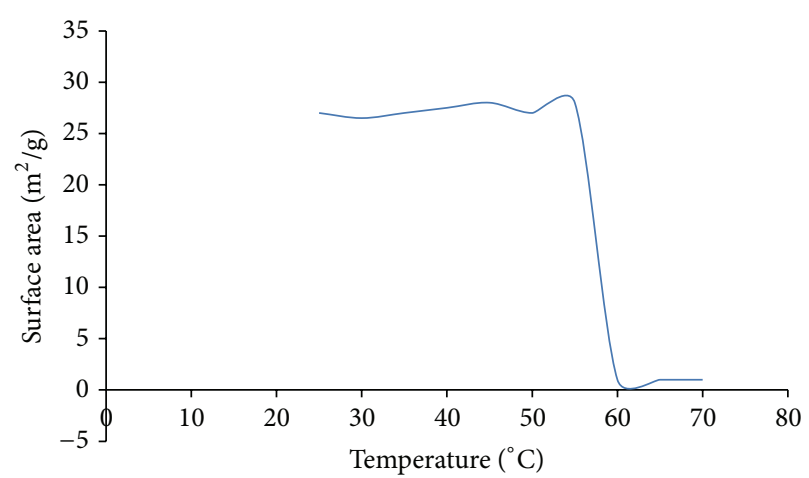

FIGURE 10: Variation of surface area with respect to temperature.

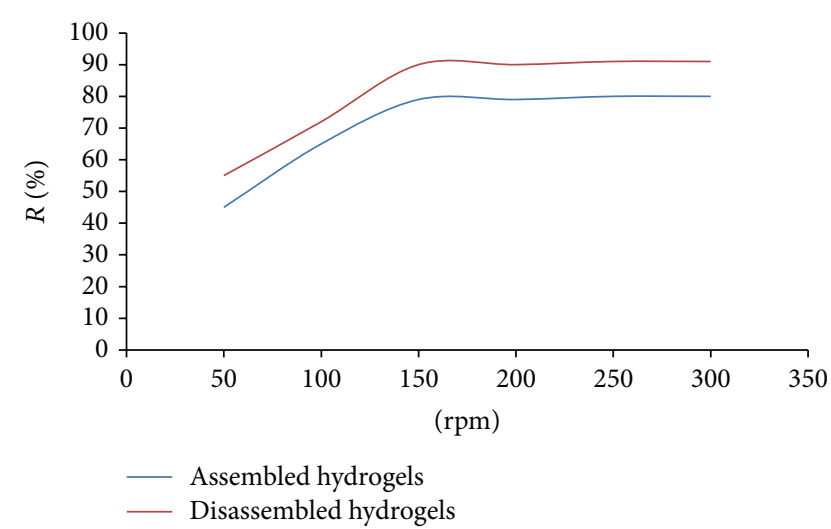

FIGURE 11: Effect of agitation speed on the removal of dye (temperature $28^{\circ} \mathrm{C}, \mathrm{pH}=6.0$, and hydrogels $0.1 \mathrm{~g}$ ).

compound unit rather than individual pieces. This implies that disassembly cannot happen with these hydrogels above $60^{\circ} \mathrm{C}$ and therefore the vessel containing such hydrogels must be maintained below this temperature (see Figure 10).

\subsubsection{Adsorption Studies}

Effect on Agitation Speed. The effect of agitation speed on the removal of the dye was studied by varying the speed of agitation from 50 to $300 \mathrm{rpm}$. The concentration of the adsorbent and the contact time were kept constant. The removal of crystal violet increased from 0 to $100 \mathrm{rpm}$ of the agitation speed and later the crystal violet dye removal was not changed appreciably as showed in Figure 11. This implies that the agitation speed in the range of $100-150 \mathrm{rpm}$ (rotation per minute) is enough to confirm the maximum cationic sites in the pores of the hydrogels readily available for the uptake of the dye. For all the rest of the experiments $150 \mathrm{rpm}$ was chosen as optimum agitation speed.

Effect of $\mathrm{pH}$. The adsorption showed a maximum at $\mathrm{pH}=$ 5.2 to 6.1 and it shows that the dye is better removed by the hydrogels in slightly acidic range than the neutral or basic. The adsorption of dye was found to be decreased after the maxima. The $\% R$ was better for the disassembled hydrogels 


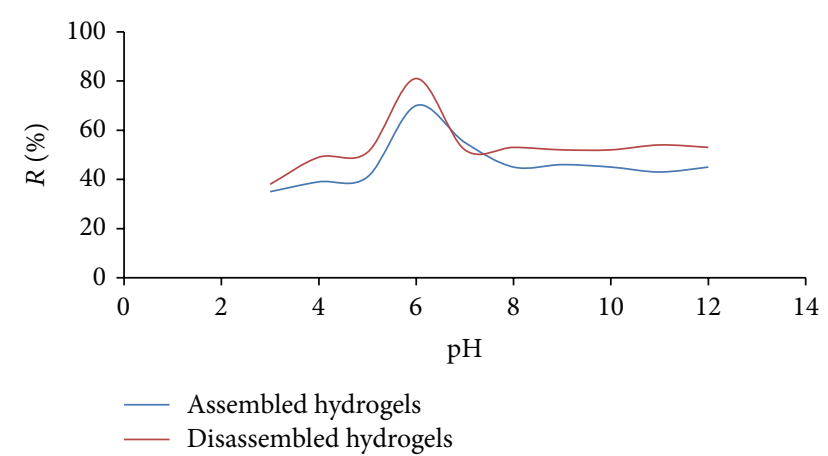

FIGURE 12: The effect of $\mathrm{pH}$ on the adsorption of dye (temperature $28^{\circ} \mathrm{C}$, hydrogel $0.1 \mathrm{~g}$, stirring speed $=150 \mathrm{rpm}$ ).

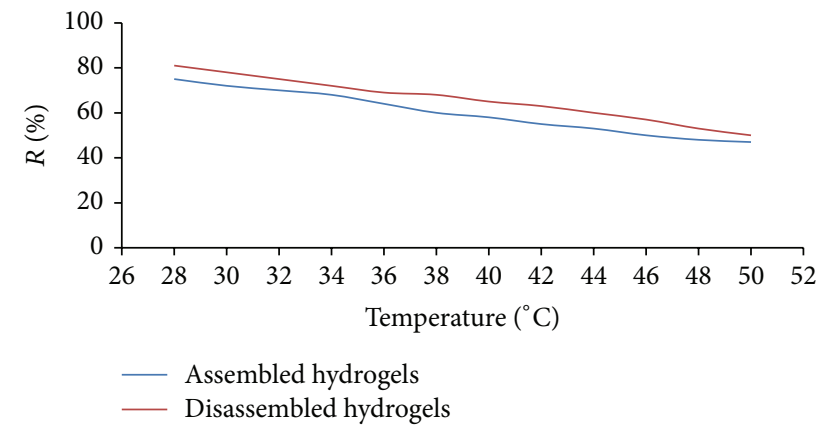

FIGURE 13: Effect of temperature on $\% R$.

than its counterpart. For both, the $\mathrm{pH}$ range maxima were in the same region, since the molecular formulas of both are not greatly changed. This is shown in Figure 12. For all other experiments $\mathrm{pH}$ was kept constant at 6.0.

Effects of Temperature. The effect of increasing temperature on the removal of the dye onto the hydrogels was studied by doing the adsorption experiment in a temperature range of $28-50^{\circ} \mathrm{C}$ and the results are shown in Figure 13. The adsorption of the dye was found decreased after $30^{\circ} \mathrm{C}$. This showed the exothermic nature of the adsorption process. Thus it was concluded not to carry out the adsorption process of crystal violet dye using poly(AMPS-co-IA) hydrogels at a lesser possible temperature. There was a notable difference in $\% R$ between the assembled and disassembled hydrogels. Disassembled hydrogels showed improvement in the adsorption of the dye when compared to that of the assembled one. The adsorption process was not carried out after $50^{\circ} \mathrm{C}$ as the amorphous nature of hydrogels would get changed to fluid nature. The decrease was similar for both the disassembled and assembled hydrogels.

\section{Conclusions}

The usually purposeless and least respected waste material, husk ashes of Pm, have been utilized for a new job in this research work. It has been shown that its ash can be used for deciding the size and surface of the soft substances, namely, poly(AMPS-co-IA) hydrogels. Using FTIR spectrum, it has been identified that $\mathrm{C}=\mathrm{O}$ stretching of IA that was found originally in free hydrogels, that appeared when white ash was included in its network. This is due to the conversion of $\mathrm{C}=\mathrm{O}$ into $\mathrm{C}-\mathrm{O}-\mathrm{Si}$ and is confirmed by the subsequent frequency of the hydrogels composite white ash. Disassembling of synthetic hydrogels such as poly(AMPS-co-IA) was achieved using husk ash of Pm as the trigger, only when the temperature of heating the husk was strong enough. The advantage of disassembling the synthetic polymer is that disassembled hydrogels were found to be more useful for the adsorption of crystal violet dye from the aqueous solution than its assembled counterpart. Also the use of husk ash of Pm is recommended owing to its ability to disassemble the hydrogels. The resultant hydrogels acquired rough surface because of the greater affinity of the "Si" moiety towards the water. This research idea suggests new applications for the husk ashes of millets such as rice and Pm when used within the network of the synthetic hydrogels. Moreover, the efficiency of the hydrogels may be improved if they were used in the disassembled form for the purposes such as drug delivery and regenerative medicine.

\section{Conflict of Interests}

The authors declare that there is no conflict of interests regarding the publication of this paper.

\section{Acknowledgment}

The authors are glad to acknowledge STIC-CUSAT, Cochin, SAIF-IITM, Chennai, and the Department of Physics, Annamalai University, Chidambaram, for their useful contributions in FTIR analysis and SEM analysis, respectively.

\section{References}

[1] M. A. Barakat, "New trends in removing heavy metals from industrial wastewater," Arabian Journal of Chemistry, vol. 4, no. 4, pp. 361-377, 2011.

[2] J. A. Zimberlin, N. Sanabria-Delong, G. N. Tew, and A. J. Crosby, "Cavitation rheology for soft materials," Soft Matter, vol. 3, no. 6, pp. 763-767, 2007.

[3] A. S. Hoffmann, "Hydrogels for biomedical applications," Advanced Drug Delivery Reviews, vol. 54, no. 1, pp. 3-12, 2002.

[4] N. A. Peppas, Y. Huang, M. Torres-Lugo, J. H. Ward, and J. Zhang, "Physicochemical foundations and structural design of hydrogels in medicine and biology," Annual Review of Biomedical Engineering, vol. 2, pp. 9-29, 2000.

[5] X. Y. Hu and Y. B. Chen, "Adsorption properties of chemical crosslinked polymer gel," Advanced Materials Research, vol. 8788, pp. 22-26, 2009.

[6] R. Coskun, "Removal of cationic dye from aqueous solution by adsorption onto crosslinked poly(4-vinylpyridine/crotonic acid) and its N-oxide derivative," Polymer Bulletin, vol. 67, no. 1, pp. 125-140, 2011.

[7] S. Çavuş and G. Gürdağ, "Noncompetitive removal of heavy metal ions from aqueous solutions by poly[2-(acrylamido)2-methyl-1-propanesulfonic acid-co-itaconic acid] hydrogel," Industrial and Engineering Chemistry Research, vol. 48, no. 5, pp. 2652-2658, 2009. 
[8] S. Çavuş and G. Gürdağ, "Competitive heavy metal removal by poly(2-acrylamido-2-methyl-1-propane sulfonic acid-coitaconic acid)," Polymers for Advanced Technologies, vol. 19, no. 9, pp. 1209-1217, 2008.

[9] J. A. Bumpus and B. J. Brock, "Biodegradation of crystal violet by the white rot fungus Phanerochaete chrysosporium," Applied and Environmental Microbiology, vol. 54, no. 5, pp. 1143-1150, 1988.

[10] Y. I. Yang, D. W. Jung, D. G. Bai, G. S. Yoo, and J. K. Choi, "Counterion-dye staining method for DNA in agarose gels using crystal violet and methyl orange," Electrophoresis, vol. 22, no. 5, pp. 855-859, 2001.

[11] E. Q. Adams and L. Rosenstein, "The color and ionization of crystal-violet," Journal of the American Chemical Society, vol. 36, pp. 1452-1473, 1914.

[12] C. C. Chen, H. J. Liao, C. Y. Cheng, C. Y. Yen, and Y. C. Chung, "Biodegradation of crystal violet by Pseudomonas putida," Biotechnology Letters, vol. 29, no. 3, pp. 391-396, 2007.

[13] W. Au, S. Pathak, C. J. Collie, and T. C. Hsu, "Cytogenetic toxicity of gentian violet and crystal violet on mammalian cells in vitro," Mutation Research, vol. 58, no. 2-3, pp. 269-276, 1978.

[14] R. Usha, "Little millet (Panicum miliare 1.) - a source of functional food for sustainable nutrition security," in Proceedings of the 7th Asia Pacific Conference on Clinical Nutrition, Bangkok, Thailand, June 2011.

[15] A. Bozkurt, O. Ekinci, and W. H. Meyer, "Synthesis and characterization of proton-conducting copolymers on the basis of vinylpyrrolidone and acrylamido sulfonic acid," Journal of Applied Polymer Science, vol. 90, no. 12, pp. 3347-3353, 2003.

[16] F. Rosa, J. Bordado, and M. Casquilho, "Hydrosoluble copolymers of acrylamide-(2-acrylamido-2-methylpropanesulfonic acid). Synthesis and characterization by spectroscopy and viscometry," Journal of Applied Polymer Science, vol. 87, no. 2, pp. 192-198, 2003.

[17] J. Travas-Sejdic and A. Easteal, "Study of free-radical copolymerization of acrylamide with 2-acrylamido-2-methyl-1propane sulphonic acid," Journal of Applied Polymer Science, vol. 75, no. 5, pp. 619-628, 2000.

[18] B. L. Rivas, S. A. Pooley, M. Luna, and K. E. Geckeler, "Synthesis of water-soluble polymers containing sulfonic acid and amine moieties for the recovery of metal ions using ultrafiltration," Journal of Applied Polymer Science, vol. 82, no. 1, pp. 22-30, 2001.

[19] O. G. Marambio, G. D. C. Pizarro, M. Jeria-Orell, M. Huerta, C. Olea-Azar, and W. D. Habicher, "Poly(N-phenylmaleimideco-acrylic acid)-copper(II) and poly(N-phenylmaleimide-coacrylic acid)-cobalt(II) complexes: synthesis, characterization, and thermal behavior," Journal of Polymer Science A: Polymer Chemistry, vol. 43, no. 20, pp. 4933-4941, 2005.

[20] K. F. Arndt, A. Richter, S. Ludwig et al., "Poly(vinyl alcohol)/ poly(acrylic acid) hydrogels: FT-IR spectroscopic characterization of crosslinking reaction and work at transition point," Acta Polymerica, vol. 50, no. 11-12, pp. 383-390, 1999.

[21] M. R. Alexander, S. Payan, and T. M. Duc, "Interfacial interactions of plasma-polymerized acrylic acid and an oxidized aluminium surface investigated using XPS, FTIR and Poly(acrylic acid) as a model compound," Surface and Interface Analysis, vol. 26, no. 13, pp. 961-973, 1998.

[22] J. Dong, Y. Ozaki, and K. Nakashima, "FTIR studies of conformational energies of poly (acrylic acid) in cast films," Journal of Polymer Science B: Polymer Physics, vol. 35, no. 3, pp. 507-515, 1997.
[23] J. G. Noh, Y. J. Sung, K. E. Geckeler, and S. E. Kudaibergenov, "Synthesis, characterization, and stimuli-sensitive properties of novel polycarbobetaines," Polymer, vol. 46, no. 7, pp. 2183-2190, 2005.

[24] J. D. S. Candido, R. C. F. Leitão, N. M. P. S. Ricardo, J. P. A. Feitosa, E. C. Muniz, and F. H. A. Rodrigues, "Hydrogels composite of poly(acrylamide-co-acrylate) and rice husk ash. I. Synthesis and characterization," Journal of Applied Polymer Science, vol. 123, no. 2, pp. 879-887, 2012.

[25] E. Suito, M. Arakawa, and T. Arakawa, "Surface area measurement of powders by adsorption in liquid phase-calculation of specific surface area of calcium carbonate powders from the adsorption of stearic acid," Journal of Chemical Society of Japan, vol. 75, pp. 596-599, 1954.

[26] L. Zhang, F. Rakotondradany, A. J. Myles, H. Fenniri, and T. J. Webster, "Arginine-glycine-aspartic acid modified rosette nanotube-hydrogel composites for bone tissue engineering," Biomaterials, vol. 30, no. 7, pp. 1309-1320, 2009.

[27] A. Groza, A. Surmeian, M. Ganciu, and I. I. Popescu, "Infrared spectral investigation of organosilicon compounds under corona charge injection in air at atmospheric pressure," Journal of Optoelectronics and Advanced Materials, vol. 7, no. 5, pp. 2545-2548, 2005.

[28] L. J. Bellamy, The Infrared Spectra of Complex Molecules, vol. 1, John Wiley \& Sons, New York, NY, USA, 3rd edition, 1975.

[29] Q. Xing, Modeling mechanisms of water affinity and condensation on Si-based surfaces via experiments and applications [Ph.D. thesis], Arizona State University, 2011.

[30] O. Kulygin and M. S. Silverstein, "Porous poly(2-hydroxyethyl methacrylate) hydrogels synthesized within high internal phase emulsions," Soft Matter, vol. 3, no. 12, pp. 1525-1529, 2007.

[31] M. V. Flores-Merino, S. Chirasatitsin, C. Lopresti, G. C. Reilly, G. Battaglia, and A. J. Engler, "Nanoscopic mechanical anisotropy in hydrogel surfaces," Soft Matter, vol. 6, no. 18, pp. 4466-4470, 2010.

[32] M. A. Azagarsamy, P. Sokkalingam, and S. Thayumanavan, "Enzyme-triggered disassembly of dendrimer-based amphiphilic nanocontainers," Journal of the American Chemical Society, vol. 131, no. 40, pp. 14184-14185, 2009. 

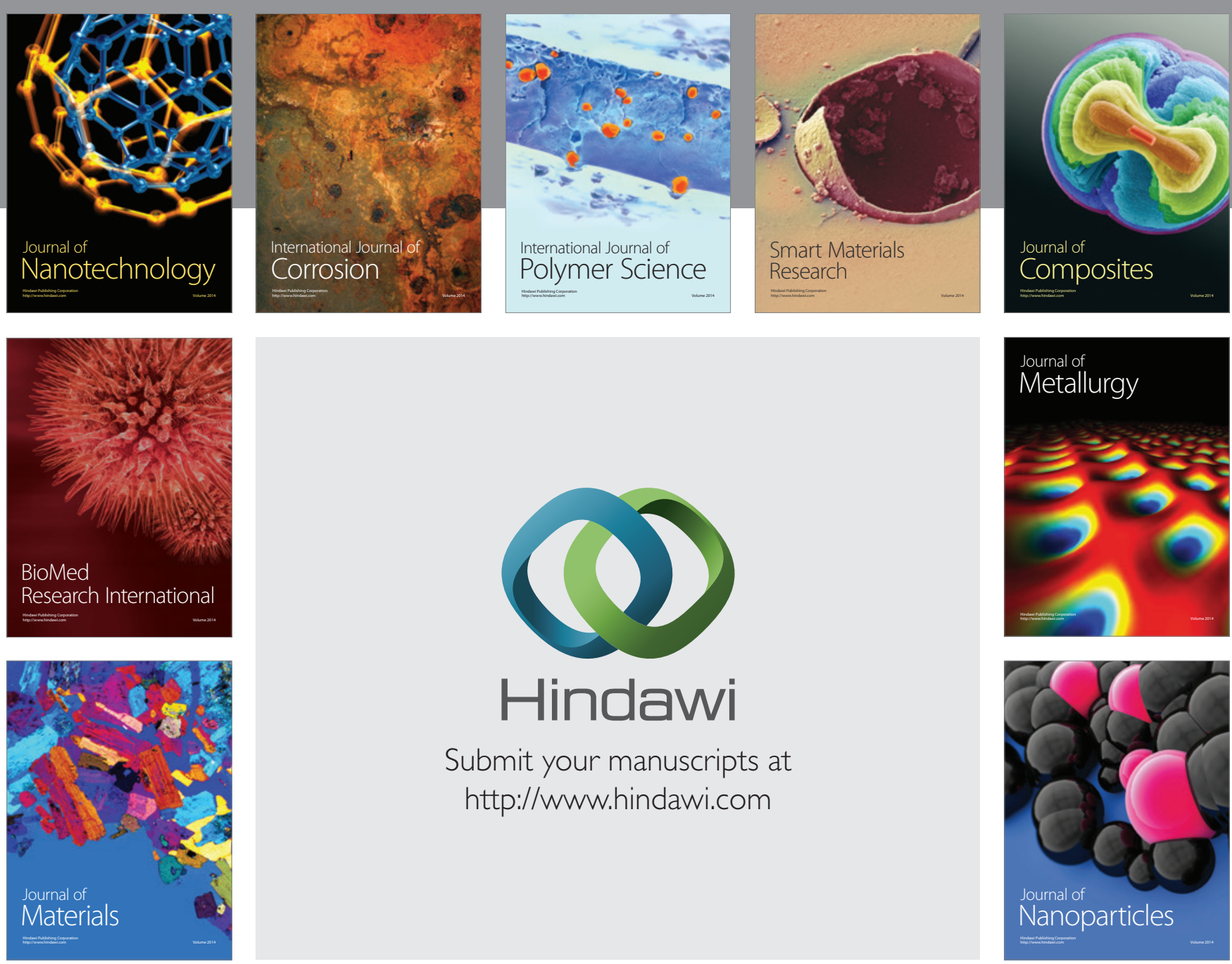

Submit your manuscripts at http://www.hindawi.com
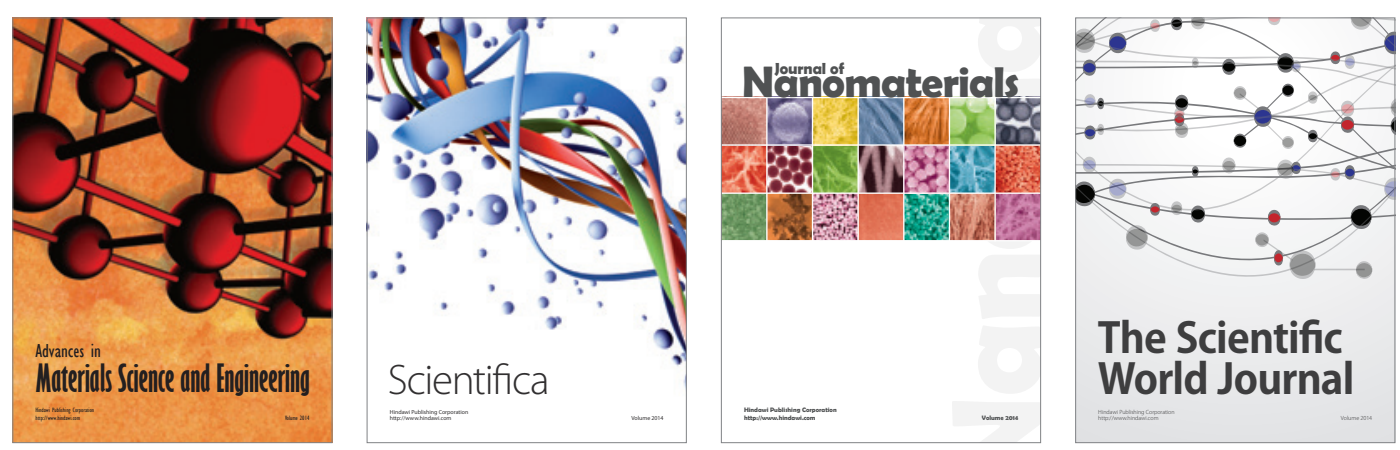

\section{The Scientific World Journal}
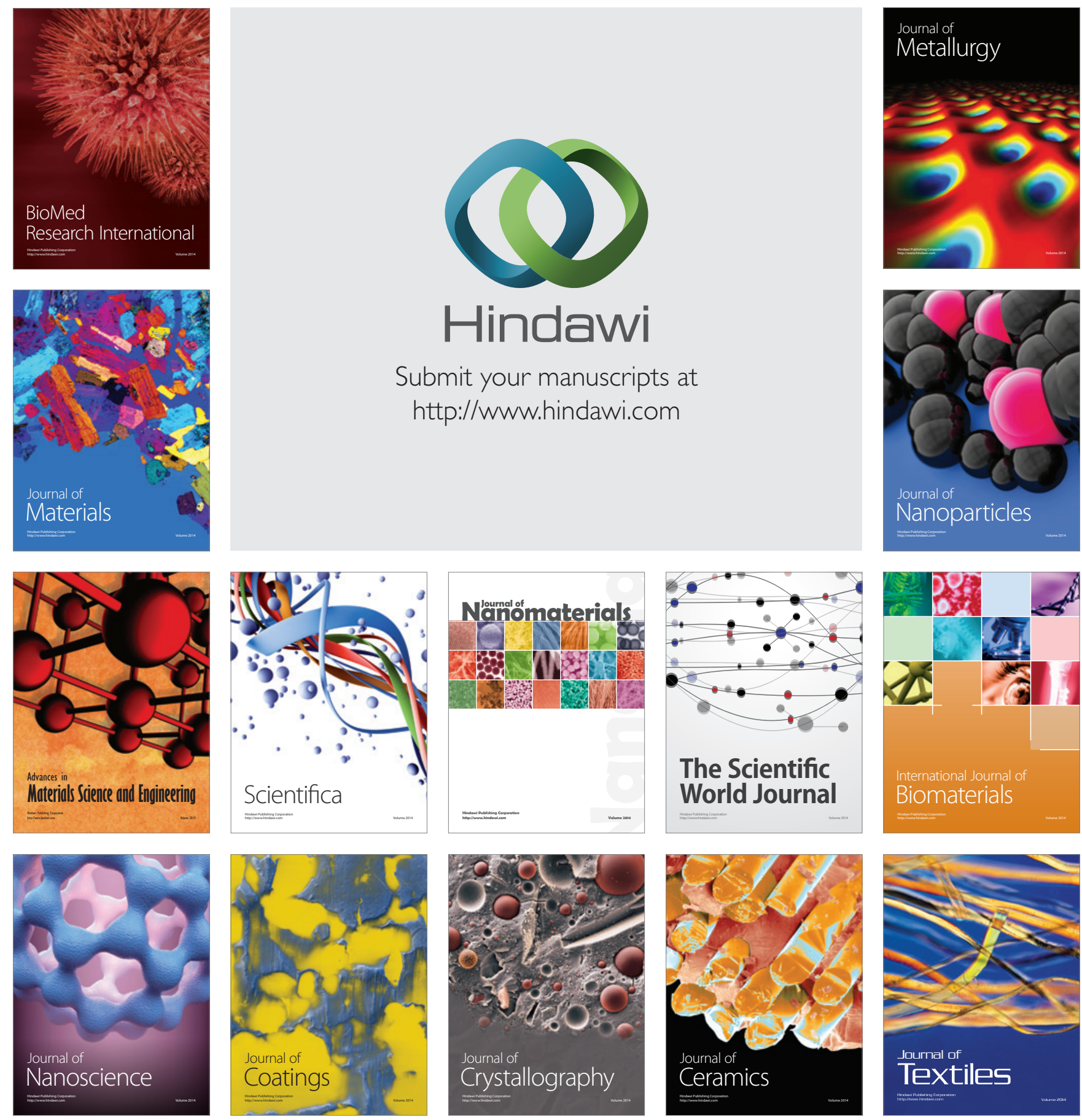